\title{
Teaching Assistant Training to Enhance Graduate ENGINEERING EDUCATION
}

\author{
Susan Caines, Dr. Leonard Lye, and Mohammed Raju Hossain \\ Faculty of Engineering and Applied Science \\ Memorial University of Newfoundland \\ St. John's, Newfoundland, A1B 3X5, Canada \\ susan.caines@mun.ca; llye@mun.ca; mrhossain@mun.ca
}

\begin{abstract}
Graduate student teaching assistant (TA) training is a one-day intensive program at Memorial University's Faculty of Engineering and Applied Science that introduces new graduate students to the roles and responsibilities of being an effective TA. This program uses online tools, case studies and theory discussions to orient new TA's to teaching and learning practices. A recent survey of graduate students taken after completion of the TA training led to modification of the current program. This paper will outline the program, proposed changes to the program and demonstrate how adapting student feedback can contribute to continuous improvements in student education.
\end{abstract}

Keywords: TA training, formative evaluation, active learning.

\section{INTRODUCTION}

Memorial University's Faculty of Engineering and Applied Science (FEAS) value the role of graduate students as assistants in engineering education. As part of the qualification program for new teaching assistants (TA), FEAS requires potential TA to complete a one day intensive program that introduces the future TA to the roles and responsibilities of a TA position. The Engineering TA training program (ENGTATP) is successful and gives students the basics of what to expect in their new roles. Along with this program, the faculty encourages excellence through the recognition of outstanding TAs with an annual award that is given to deserving TAs through recommendations from faculty and students.

ENGTATP gives new TAs an introduction to the activities expected in the FEAS - from marking assignments and papers to running tutorials and lecturing. The training also outlines university policies including academic misconduct, plagiarism, privacy and harassment. To help new students succeed in their first TA assignment the current training includes discussions on qualities of an effective TA, grading techniques, lessons on communicating in the classroom, and tips on dealing with problems. The course concludes with practice lab sessions where students visit laboratory facilities and a "what to do for your first lab" demonstration is conducted. An open Q \& A is held after the formal lessons and an award ceremony conducted to end the day. Training is completed in a one-day session on a Saturday mid-way through each term. Students each receive a manual with additional and more in-depth information for future reference.

The ENGTATP is facilitated by the Associate Dean of Graduate Studies and two experienced TAs. The intent of this diversity is to bring different perspectives to the new TAs and to encourage an open, frank discussion.

This training program has been in place since 2011 and is provided once a semester (3 times a year). All aspects needed to begin a successful TA career are included and students have given anecdotal evidence of satisfaction in casual conversation. Faculty members have not expressed any systematic dissatisfaction with new TAs. Due to this apparent full satisfaction of the course, no formal reflection on the course was done.

In 2012, during an ENGTATP question period, a student asked how to find a rubric if their supervisor did not provide one. At the time there was no mechanism in place to distribute general material to TA. This prompted the design of a web based TA Toolbox to aid in continued TA support. The TA Toolbox is located in Memorials Desire2learn (D2L) system. Site access is limited to graduate students who have completed the TA training and contains the course information as well as additional documents and links to support continued learning. Additional examples of tools like rubrics are included and links writing center tools to improve marking are provided. A discussion forum called TA Talk is used to answer questions and provide guidance when needed in an informal manner.

Improvement of the training based on these informal discussions lead the facilitators to reflect on other improvements that could enhance the program and 
improve student learning. Improvements in the TA training program would strengthen a successful program and lead to improvements in faculty/TA relations, Student/TA relations and improve the quality of undergraduate education at Memorial University.

This paper will show how the incorporation of participant feedback can improve a TA training program.

\section{SOLICITING FEEDBACK}

Participant feedback can be solicited in many formal and informal ways, from formal surveys such as course evaluation questionnaires (CEQs) used for all MUN courses to informal discussions with one or two participants. The term formative evaluation traditionally indicates that the information gathered will be used for some type of modification. This can be modification of student learning, course design, scholastic achievement [1]. Formative feedback from students seeks to find areas for improvement [2]. To improve the ENGTATP a Stop/Start/Continue technique was used to gather information on the training session.

\subsection{Start/Stop/Continue}

Start Stop Continue is a common formative evaluation technique that aims to solicit written responses from students [2], [3].

This technique asks three questions:

1. What is one thing we should STOP doing?

2. What is one thing we should START doing?

3. What is one thing we should CONTINUE doing?

Question 1 looks to make the students consider what was not working in the session; what they did not find useful. Question 2 gave students an opportunity to consider what they felt was missing from the course; areas for improvement. The final question asked what was done well or what the student felt was important to keep in the session.

ENGTATP typically has between 15 - 40 participants each session. In October 2013, 38 new graduate students completed the original program. At the close of the day, all participants were asked to complete the Stop/Start/Continue survey. They were given the option of anonymously submitting their opinion to encourage honest and constructive feedback. Of the 38 participants, 29 students voluntarily submitted responses with six providing only positive "continue" comments.

The answers to question 1 (Start) were consolidated into 3 different points for consideration.

- Change time: Requests to divide the course into 2 half-day sessions or to have the training on a weekday
- More interactive elements: Requests for more cases, variety, and discussion.

- More personal examples: Requests for more real life experiences from current TAs

The answers to question 2 (Stop) were consolidated into 3 different points for consideration.

- Distracting slides

- Repetitive information

- Lecture style

The answers to question 3 (Continue) were consolidated into 4 different points for consideration.

- Small group work

- Energetic and engaging lectures

- Name tags

- Case discussion

From this feedback, two categories were selected for immediate implementation.

1. Interaction

2. Presentation

\section{PROGRAM CHANGE}

In response to the Start/Stop/Continue evaluation improvements were developed to increase student participation and interaction. This increase should lead to the opportunity for improving communication skills. This addressed the most frequent Start/Stop suggestions and builds on the positive feedback from the Continue section.

Many students indicated an increase in interactive elements would improve the ENGTATP. They indicate that it would both improve learning and help them fit in better in a new environment. Many students in the ENGTATP are new to the community and country. The majority $(80 \%)$ of new graduate students are international and English is their second language.

Active learning is used to engage students in the learning process in a dynamic way [4]. Traditional lectures, while important and necessary, are considered a passive technique. This type of learning helps students play an active role in their learning and help support graduate attributes like lifelong learning and communication skills [5]. Additionally, activities that require participation from students keep the students more interested and engaged in the material.

In the 2011 program, there are two main activities that require active participation in the material. Students are broken into groups of 4-5 and are asked to sit with their team. ENGTATP is offered to all engineering disciplines and these small groups can be an opportunity for students to make contacts in disciplines other than their own. 
The first activity is a discussion; the students are asked the question "What qualities do you think a TA should have to be effective and why?" The students are given time to discuss the question and compile a list of important characteristics. The groups are brought together and a class list of common characteristics is developed.

A case study near the end of the session gives students an opportunity to work in small groups and discuss a fictional case. The students are asked to read and discuss a case and decide in their groups what the major issues are, what the fictitious TA should do, and if there was any way to prevent the issues earlier in. The students then present their case to the rest of the class. This part of the session is the most popular and gives students an opportunity to practice what they've learned and allows them to interact with their peers.

While these elements are successful, the Start/Stop/Continue feedback indicates that more such interactions are needed. To facilitate this, the program presentation was reviewed to determine areas for improvement. The following active learning activities were added to improve student engagement:

- An early discussion was added to encourage students to discuss the importance of meeting with the Instructor. This small group activity gives the students an opportunity to reflect on the lecture and to discuss fears and concerns in a safe environment.

- To begin the lesson on classroom diversity, students are asked to discuss what they think makes a diverse classroom. This helps students realize that diversity goes beyond race and culture and opens discussion on how to develop skills on inclusion.

- A two part paper grading activity is introduced to demonstrate the usefulness and application of grading rubrics. After a general introduction to marking student work, new TAs are asked to read a short paper and assess a grade out of 10 . The marks are compared and discussion about the subjectivity of marking is encouraged. After an introduction to rubrics, the students are asked to re-assess the paper using the condensed rubric provided.

- To help ESL students feel more comfortable in a uniquely Canadian community, an exercise was developed to introduce some common local phrases to students and to demonstrate the importance of clarity in communication.

To increase networking and facilitate participation, students were re-grouped at each break and divided into new activity groups. This allows students to meet many colleagues that they may not have the opportunity to connect with during their academic program.

\section{RESULTS AND DISCUSSION}

The modified ENGTATP was presented to a new group of graduate students in February 2014. Seventeen students participated in the updated program and a Stop/Start/Continue evaluation was done at the end of the session to determine if the changes improved the feedback. Fifteen students voluntarily submitted responses.

Responses were much less detailed and varied than the Fall 2013 evaluation. Table 1 summarizes the general comments from the Winter 2014 Stop/Start/Continue feedback. While there remain suggestions for more activities, they are more specific to the content. In the Fall 2013 feedback, the requests for more interaction/less lecture was general and from most students. This indicated that there were not enough active learning opportunities. After the changes, the feedback indicates that there is a good balance between lecture and activity and that students were generally engaged in the learning.

Table 1: Winter 2014 Stop/Start/Continue Summary

\begin{tabular}{|l|l|l|}
\hline \multicolumn{1}{|c|}{ Start } & \multicolumn{1}{c|}{ Stop } & \multicolumn{1}{c|}{ Continue } \\
\hline $\begin{array}{l}\text { Role play: Practice } \\
\text { dealing with } \\
\text { problems/conflicts } \\
\text { More practice } \\
\text { sessions }\end{array}$ & Starting early & Good food \\
& $\begin{array}{l}\text { Starting early } \\
\text { in the } \\
\text { morning }\end{array}$ & $\begin{array}{l}\text { Lab } \\
\text { demonstration }\end{array}$ \\
& & Group work \\
& & Humour \\
\hline
\end{tabular}

\section{CONCLUSION}

The use of formative evaluation to improve teacher assistant training was successfully applied to modify training at the Faculty of Engineering and Applied Science, Memorial University. Feedback from participants indicated that more interactive learning was needed to keep students interested and engaged. Four new activities were developed to increase opportunities for students to interact with the material and each other. Feedback after the presentation of the more interactive session in winter 2014 indicated that the implementation of new elements was successful and students were more satisfied with the level of engagement.

\section{RECOMMENDATION}

To support continuous improvement, it is recommended that the remaining feedback be evaluated for future change.

- Investigation of implementation of a role playing activity to improve conflict resolution 
- Faculty feedback should be solicited to determine gaps in TA preparedness

- Ongoing support to new TAs through implementation of a mentorship program [6].

\section{References}

[1] D. Wiliam, "Formative Assessment:Getting the Focus Right," EDUCATIONAL ASSESSMENT, vol. 11, pp. 283-289, 2006.

[2] J. W. George and J. Cowan, A handbook of techniques for formative evaluation: mapping the student's learning experience, Kogan Page Ltd., 1999.

[3] C. Bovill, "Sharing responsibility for learning through formative evaluation: moving to evaluation as learning," Practice and Evidence of the Scholarship of Teaching and Learning in Higher Education, pp. 96-109, 2001.

[4] M. Prince, "Does Active Learning Work? A review of the Research," Journal of Engineering Education, p. 223, 2004.

[5] E. de Graaff, G. Saunders-Smits and M. Nieweg, Research and Proctice of Active Learning in Engineering Education, Amsterdam University Press, 2005.
[6] B. Stephenson, A. Kuipers, R. K. Adl and F. Stephenson, "Teaching Assistant in Residence: A Novel Peer Mentorship Program for Less Experienced Teaching Assistants," Journal of Computing Sciences in Colleges, vol. 29, no. 4, pp. 183-190, April 2014.

[7] S. Stevens, "A "Dramatic" Approach to Improving the Intelligibility of ITAs," English for Specific Purposes, vol. 8, pp. 181-194, 1989.

[8] S. Jenkins, "Cultural and linguistic miscues: a case study of international teaching assistant and academic faculty miscommunication," International Journal of Intercultural Relations, 2000.

[9] L. H. McWilliams, S. E. Silliman and C. Pieronek, "Modifications to a Freshman Engineering Course Based on Student Feedback," in Proceedings of the 2004 American Society for Engineering Education Annual Conference \& Exposition, 2004.

[10] G. F. Hoban, "Enhancing action learning with student feedback," Action Learning: Research and Practice, vol. 1, no. 2,2004 .

[11] J. T. E. Richardson, "Instruments for obtaining student feedback: a review of the literature," Assessment \& Evaluation in Higher Education, vol. 30, no. 4, pp. 387415, 2005. 